\title{
Effect of Nitrogen Nutritional Stress on some Mineral Nutrients and Photosynthetic Apparatus of Zea mays L. and Vigna unguiculata L.
}

\author{
Akinbode Foluso OLOGUNDUDU ${ }^{1 *}$, Adekunle Ajayi ADELUSI² \\ ${ }^{1}$ Wesley University of Science and Technology, College of Natural and Applied Sciences, Department of Biological \\ Sciences, P.M.B. 507, Ondo, Ondo State, Nigeria; akinbodefoluso@yahoo.com ( ${ }^{*}$ corresponding author) \\ ${ }^{2}$ Obafemi Awolowo University, Department of Botany, Ile-Ife, Nigeria
}

\begin{abstract}
The study investigated the responses of maize (Zea mays L.) and cowpea (Vigna unguiculata L. Walp.) seedlings metabolic activities and photosynthetic apparatus to nitrogen nutritional stress. Germination of seeds was done using treated sand in sixty plastic pots and the seedlings were divided into four nutrient regimes. A group of the seedlings was nutrient stressed by administering $200 \mathrm{ml}$ of complete nutrient solution minus nitrogen $(-\mathrm{N})$ while the other groups were fed with five times $(\mathrm{X} 5 \mathrm{~N})$ and ten times $(\mathrm{X} 10 \mathrm{~N})$ the optimal concentration of nitrogen and the last regime was fed with full nutrient solution (FN). The photosynthetic parameters studied included chlorophylls 'a' and 'b' respectively; carotenes and xanthophyll while the mineral elements investigated include potassium, calcium and magnesium. The result of the growth analysis showed that nitrogen deficiency promotes an increase in the content of abscisic acid (ABA), causing stomatal closure and a reduction in photosynthesis. This explains the higher rate of leaf abscission in $-\mathrm{N}$ plants. A comparison of calcium ion and magnesium ion concentrations in both optimal and stressed conditions reveals that the two ions show antagonism in uptake. There is a correlation between nitrogen and magnesium accumulation as magnesium ion plays a vital role in chlorophyll biosynthesis, protein synthesis and photosynthesis. The pattern of accumulation of photosynthetic apparatus in both maize and cowpea follow a similar pattern. Chlorophyll a dictated the growth pattern of other photosynthetic apparatus in both Zea mays and Vigna unguiculata.
\end{abstract}

Keywords: accumulation, chlorophyll, optimal nutrient, photosynthesis, stress

\section{Introduction}

A biological stress is defined as any change in environmental conditions that might reduce or adversely change a plant growth or development (Levitt, 1980). Any change in the environment that results in plant response that is less than the optimum might be considered stressful (Salisbury and Ross, 1991). In plants, water and nutritional deficiency, high salinity and extreme temperature are some of the most studied stress factors (Lambers et al., 1998). In both natural and agricultural conditions, plants are frequently exposed to unfavorable environments that results in some degrees of stress (Hasegawa et al., 2000). Water deficit, heat stress, chilling and freezing, salinity, oxygen and nutrient are major stress factors restricting plant growth and development (Bray, 2000). In addition, stress plays a major role in determining how soil and climate limit the distribution of plant species (Shinozaki et al., 2000). The physiological process that underlies stress injury and the adaptation and acclimation mechanisms of plants to environmental stress is of huge importance to both agriculture and the environment (Hong et al., 2000) Nutrient stress can result either from the form in which the nutrient exist, the process by which they become available to the plant; content of soil solution and soil pH (Evans, 1989). The demand by a plant for a given nutrient changes with time because it is influenced by changes in all other environmental factors that control plant growth which include other nutrients, water, radiation, temperature and age among others (Hartung et al., 1998). Nutrient stress can be evaluated as the proportion by which the growth rate of the plant or crop is limited by that nutrient under the prevailing conditions. It affects all aspects of growth and so should be quantified in terms of growth parameters such as dry weight and biomass accumulation (Pollock and Cairns, 1991). The present study should serve to provide more information on the effect of nitrogen nutritional stress on some aspects of the primary metabolic activities of Zea mays and Vigna unguiculata.

\section{Materials and methods}

\section{Soil treatment and germination of seedlings}

Seedlings of Zea mays Linn. (cv. 'SWAN1') and Vigna unguiculata L. Walp. (cv. 'Ife Brown Variety') were used in the experiment. Soil was treated by soaking sand in $1 \mathrm{~N}$ hydrochloric acid for one hour to eliminate microbes and solubilize mineral elements which might be present in it. 
The acid was drained off and the sand washed with tap water and then distilled water until the $\mathrm{pH}$ of the decantable water was between 6 and 7, which was optimal for the germination and growth of the seedlings. The washed sand was air dried and transferred into sixty plastic pots (about $24 \mathrm{~cm}$ in diameter and $21 \mathrm{~cm}$ in depth) each with four holes of approximately $4 \mathrm{~mm}$ in diameter bored at the bottom to enhance drainage during the course of the experiment. Ten seeds were planted in each pot and after germination thinned to five. The plants were exposed to approximately eight hours of sunlight daily. Each bowl was supplied with $200 \mathrm{ml}$ of distilled water in the morning and evening during the first 6 days after planting. After germination and on the 7th day after planting, the pots were divided into four nutrient regimes each containing fifteen pots, each pot containing five seedlings. The experiment was arranged in a complete randomized design and carried out in five replicates.

\section{Nutrient solution composition and application of nutrient regimes}

The nutrient solution was prepared according to the modified Long Ashton Formular (Hewitt, 1952). The nutrient solution composition were given the subscripts; FN (complete nutrient solution), X5N (complete nutrient solution with five times optimal concentration of nitrogen), X10N (complete nutrient solution with 10 times optimal concentration of nitrogen), and -N (complete nutrient solution without nitrogen).

\section{Weight analysis}

Weight analyses were carried out on ten seedlings harvested at random (sampling procedure) from each nutrient regime. The plants were carefully uprooted, blotted dry, weighed fresh and then placed inside a labeled envelope and kept in a Gallenkamp drying oven set at $80^{\circ} \mathrm{C}$ to dry constant weight.

\section{Chlorophyll extraction}

Five gram each of the seedlings leaves were grounded in $20 \mathrm{ml}$ of $80 \%$ acetone using a mortar and pestle. The brew was filtered through a Whatman's No 1 filter paper. The pigment quantities in the acetone extract were determined on a CE 373 (visible) linear readout spectrophotometer at wavelength of $664 \mathrm{~nm}$ and $647 \mathrm{~nm}$, chlorophyll "a" and "b" and the total chlorophyll quantities were determined using the formula.

Chlorophyll 'a' $(\mu \mathrm{M})=13.19 \mathrm{~A} 664-2.37 \mathrm{~A} 647$

Chlorophyll ' $\mathrm{b}$ ' $(\mu \mathrm{M})=22.10 \mathrm{~A} 647-5.26 \mathrm{~A} 664$

Total Chlorophyll $(\mu \mathrm{M})=7.93 \mathrm{~A} 664+19.53 \mathrm{~A} 67$ A664 is the absorbance at $664 \mathrm{~nm}$ 1993).

$$
\text { A647 is the absorbance at } 647 \mathrm{~nm} \text { (Coombs et al., }
$$

\section{Carotenes and xanthophylls extraction}

Five gram of maize and cowpea leaves were separately macerated in $20 \mathrm{ml}$ of $80 \%$ acetone using a mortar and a pestle. The extract was filtered through a Whatman's No.1 filter paper. $25 \mathrm{ml}$ of petroleum ether was placed in a separating funnel and the acetone extract of the pigment was added. The funnel was gently rotated, releasing the pressure periodically. $35 \mathrm{ml}$ of distilled water was poured down the sides of the funnel and the funnel rotated until the upper layer was green; the two layers were allowed to separate before the lower acetone layer was then drawn off. The petroleum ether fraction was later washed with $25 \mathrm{ml}$ of distilled water at three consecutive times and discarded each time. This removed any trace of acetone that remained in the petroleum ether fraction. Twenty five (25) $\mathrm{ml}$ of $92 \%$ (v/v) methanol was added to the petroleum ether fraction, rotated and then separated into upper and lower fractions (carotenes and xanthophylls). The absorbance of both fractions was determined using Digital Spectrophotometer. Petroleum ether and diethyl ether served as blanks (Machlis and Torrey, 1956). Extraction of macronutrients ( $\mathrm{K}, \mathrm{Ca}$ and $\mathrm{Mg}$ ): for the analysis of macronutrient, a fully expanded leaf from each plant was sampled. The macronutrient was determined by the methods described by Anderson et al. (2005). One hundred mg of ground dry leaf samples was digested in $2 \mathrm{ml}$ of sulphuric peroxide digestion mixture until a clear and almost colourless solution was obtained. After digestion, the volume of the samples was made to $100 \mathrm{ml}$ with distilled deionized water, potassium was determined with a flame photometer (Jenway, PF P7), and calcium and magnesium with an atomic absorption spectrometer (Perkin Elmer Annyst 100).

\section{Statistical analysis}

A two way analysis of variance (ANOVA) was performed using Statistical Analysis System (SAS) software version 9.1 (SAS, 2003). The data were first tested between normality and assumption of constant variance. Post hoc testing was carried out using Duncan Multiple Range Test (DMRT) to separate the significance means at 0.05 , confidence limit (alpha level) for the mean.

\section{Results}

There were gradual decreases in a linear fashion in chlorophyll 'a' accumulation for a greater part of the experimental period in all treatments as shown in Fig. 1a. Both $\mathrm{X} 10 \mathrm{~N}$ and $\mathrm{X} 5 \mathrm{~N}$ were approximately equal on the $31^{\text {st }}$ day. The highest chlorophyll 'a' accumulation was recorded in $\mathrm{X} 10 \mathrm{~N}$, followed by FN while $-\mathrm{N}$ was observed to be the lowest. Results of the ANOVA showed that there were no significant difference $(p>0.05)$ in the control (FN), X5N and $-\mathrm{N}$ plants. However, $-\mathrm{N}$ was significantly different. In contrast, the chlorophyll contents of maize showed linear increase until $45^{\text {th }}$ day and decreased gradually until the end of the experiment. FN was observed to have the highest chlorophyll 'a' accumulation, followed by $\mathrm{X} 10 \mathrm{~N}$ while the lowest was observed in the $-\mathrm{N}$ treated plants. Results of the ANOVA showed that there were no significant difference $(p>0.05)$ in the control (FN), X10N and $-\mathrm{N}$ 
378

treated plants. However, X5N was significantly different. Meanwhile, the chlorophyll ' $b$ ' contents in both regimes of cowpea and maize followed similar growth pattern as shown in Fig. 2a and 2b. However, results of the ANOVA showed that there was no significant difference $(p>0.05)$ in all the treatments for cowpea regimes while there was significant difference $(p>0.05)$ in all treatments for the maize regimes. The total chlorophyll content was somewhat determined by chlorophyll 'a' as the pattern of accumulation were similar (Fig. 3a) while in maize, the total chlorophyll content follow similar growth pattern as dictated by chlorophyll ' $b$ ' contents. Results of the ANOVA showed that there was no significant difference $(p>0.05)$ in all the treatments.

The chlorophyll ' $b$ ' contents of all the regimes did not follow a similar pattern as chlorophyll 'a' (Fig. 2a). The chlorophyll contents in all the treatments were similar and they decreased linearly till the end of the experimental period. In X5N, FN and -N plants respectively, they decreased sharply between the $10^{\text {th }}$ and $17^{\text {th }}$ day followed by a rapid increase and decrease between the $17^{\text {th }}$ and $31^{\text {st }}$ day in $\mathrm{FN}$ while $\mathrm{X} 5 \mathrm{~N}$ and $-\mathrm{N}$ decreased gradually during this period. The highest value was recorded in $\mathrm{X} 10 \mathrm{~N}$, followed by $\mathrm{FN}$ while the lowest was observed in the $-\mathrm{N}$ plants.

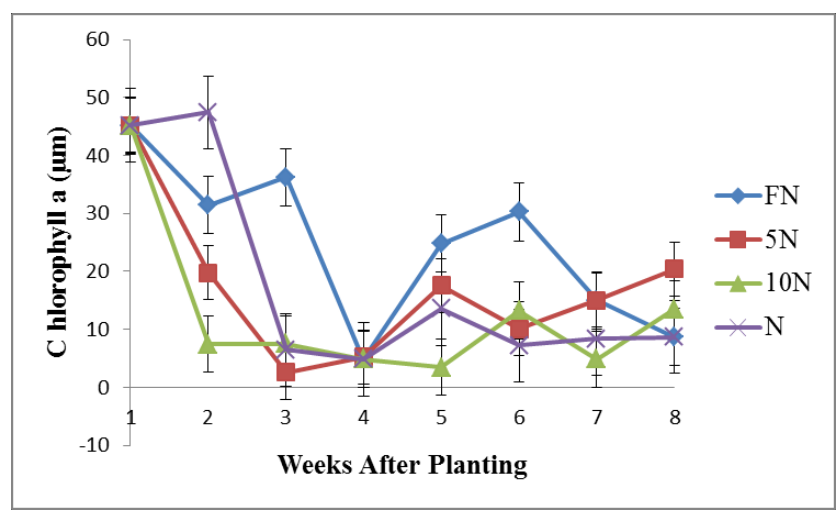

Fig. 1a. The effect of nitrogen nutritional stress on the chlorophyll a accumulation of Vigna unguiculata measured at different periods

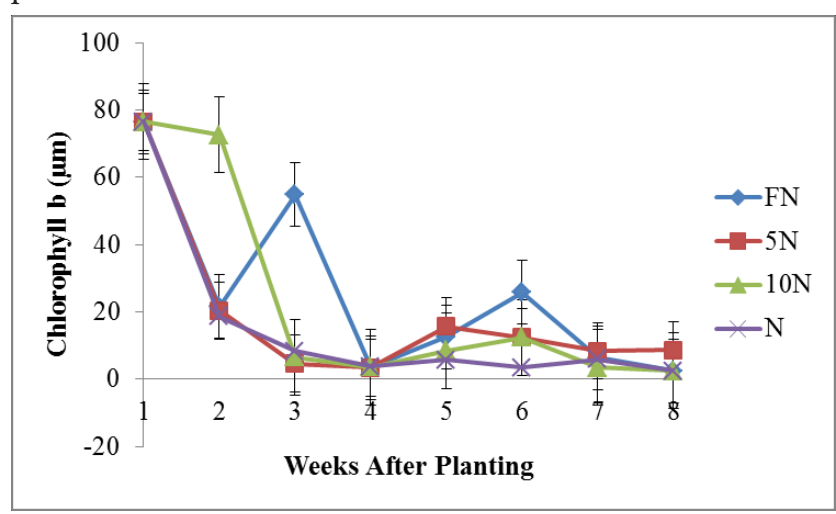

Fig. 2a. The effect of nitrogen nutritional stress on the chlorophyll b accumulation of Vigna unguiculata measured at different periods
In the same pattern like chlorophyll 'a' contents, the chlorophyll 'b' contents in maize followed similar pattern except that initial contents of chlorophyll 'a' were lower than those of chlorophyll ' $b$ ' (Fig. 1b and 2b). The X5N and $\mathrm{X} 10 \mathrm{~N}$ respectively were similar for a greater part of the experiment. Also, both plants increased gradually between the $10^{\text {th }}$ and $31^{\text {st }}$ day and later decreased till the end of the experiment. However, both FN and -N decreased for a greater part of the experiment. The $\mathrm{X} 10 \mathrm{~N}$ had the highest accumulation, followed by the $\mathrm{X} 5 \mathrm{~N}$ while the $-\mathrm{N}$ was observed to be the lowest. Results of the ANOVA showed that there was significant difference $(p<0.05)$ in all the treatments. There was no consistent pattern in the carotene contents of cowpea during the experimental period (Fig. 4a). All the plants had similar pattern of carotene accumulation on the $17^{\text {th }}$ and $45^{\text {th }}$ day respectively. The highest carotene accumulation was observed in the $\mathrm{X} 10 \mathrm{~N}$, followed by the X5N while the - $\mathrm{N}$ had the lowest. Results of the ANOVA showed that there were no significant difference $(p>0.05)$ in all the treatments. The carotene contents in maize appeared to follow similar pattern just as in maize chlorophyll 'b' content (Fig. 4b). The Carotene contents linearly increased initially reaching their peak on the $31^{\text {st }}$ and $38^{\text {th }}$ days respectively and after-

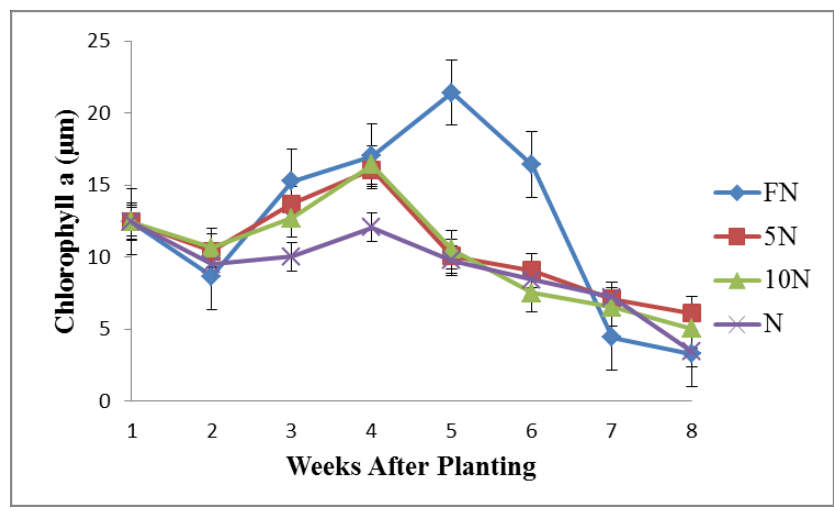

Fig. 1b. The effect of nitrogen nutritional stress on the chlorophyll a accumulation of Zea mays measured at different periods

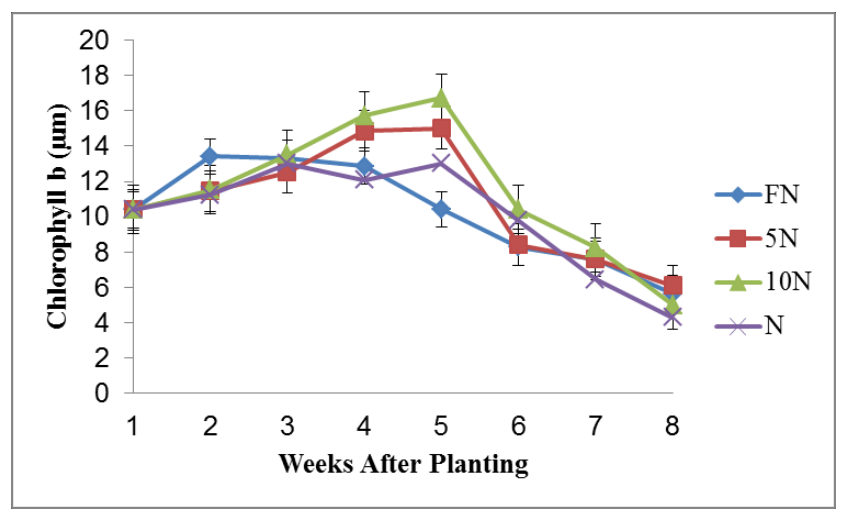

Fig. 2b. The effect of nitrogen nutritional stress on the chlorophyll $b$ accumulation of Zea mays measured at different periods 
wards decreased gradually. Results of the ANOVA showed that there was no significant difference $(p>0.05)$ in all the treatments. The xanthophyll accumulation followed similar trend as chlorophylls a and b respectively (Fig. 5a). The cowpea xanthophylls content appeared to be controlled by chlorophyll as both recorded a linear decrease throughout the experimental period. Results of the ANOVA showed that there was no significant difference $(p>0.05)$ in all the treatments. There were gradual increases in the xanthophylls accumulation of Zea mays in all the regimes for a greater part of the experimental period (Fig. 5b). How-

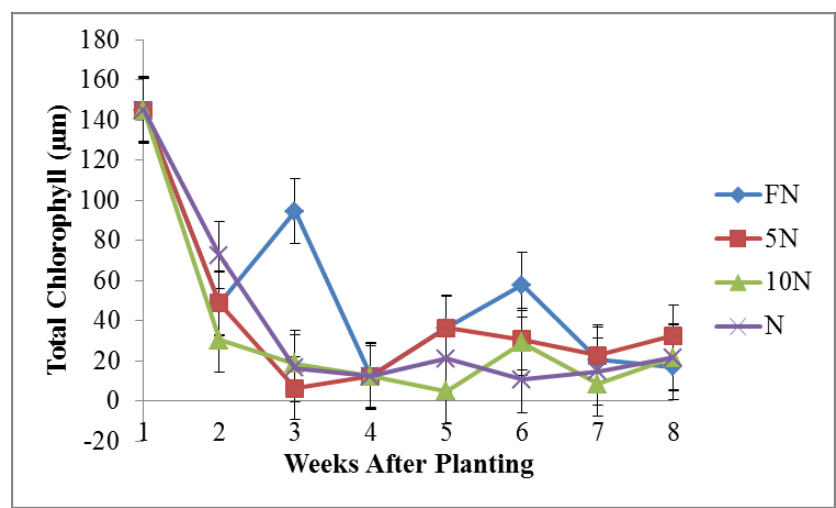

Fig. 3a. The effect of nitrogen nutritional stress on the total chlorophyll accumulation of Vigna unguiculata measured at different periods

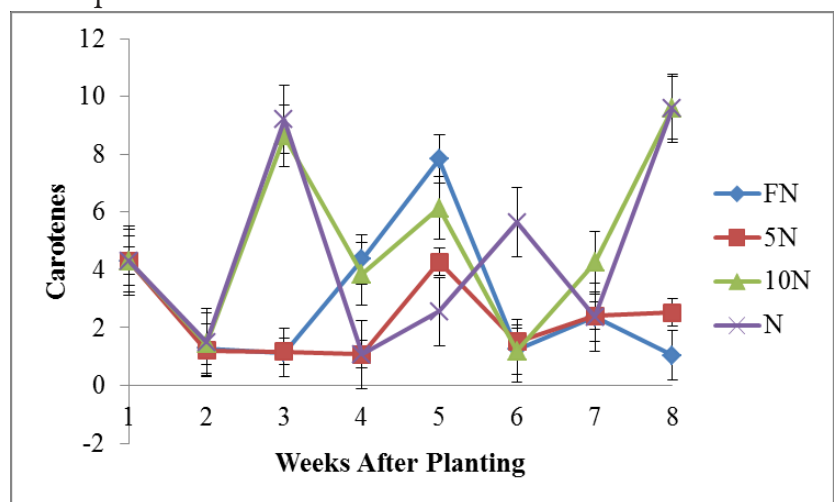

Fig. 4a. The effect of nitrogen nutritional stress on the carotene content of Vigna unguiculata measured at different periods

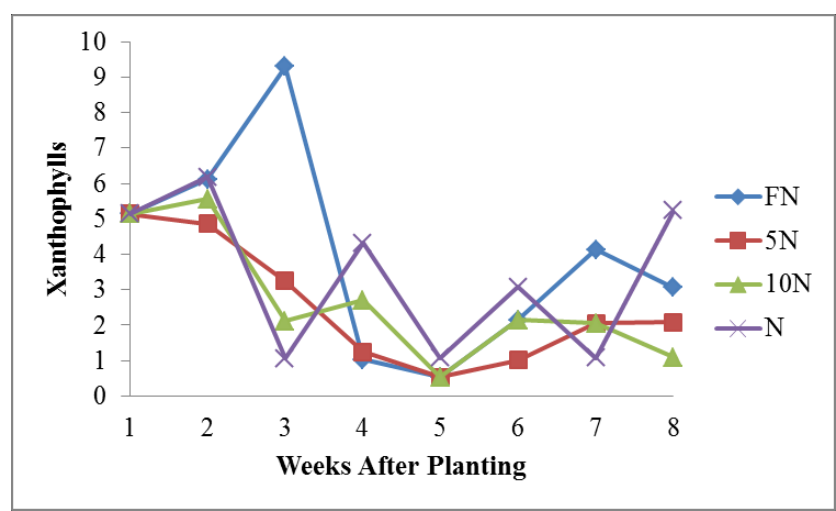

Fig. 5a. The effect of nitrogen nutritional stress on the xanthophyll content of Vigna unguiculata measured at different periods ever, the FN fell below X5N and later recovered over and above it towards the end of the experiment. Results of the ANOVA showed that there was no significant difference $(p>0.05)$ in all the treatments. Calcium and magnesium contents showed similar trend as dictated by their growth patterns in Fig. 6a and 7a. The highest percentage calcium content was observed in the FN, followed by X10N while X5N recorded the lowest. Results of the ANOVA showed that there was no significant difference $(p>0.05)$ in all the treatments. However, the highest magnesium content was observed in X5N while the lowest was recorded in FN. Re-

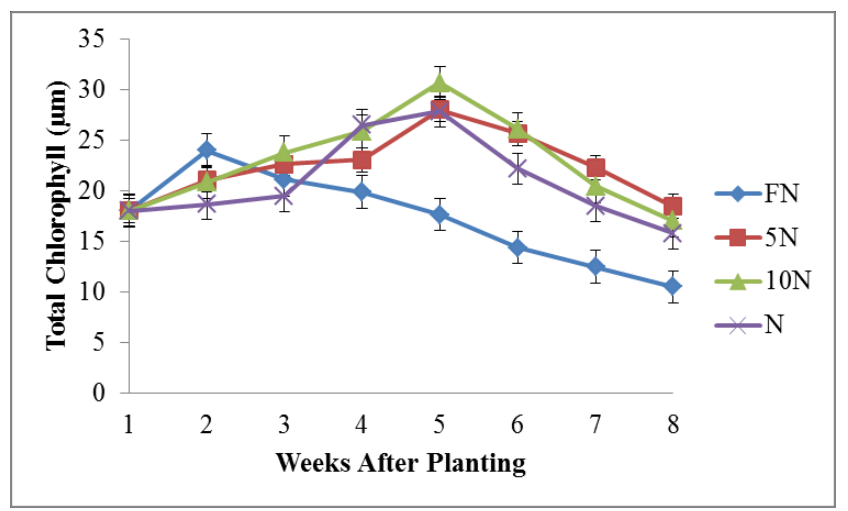

Fig. 3b. The effect of nitrogen nutritional stress on the total chlorophyll of Zea mays measured at different periods

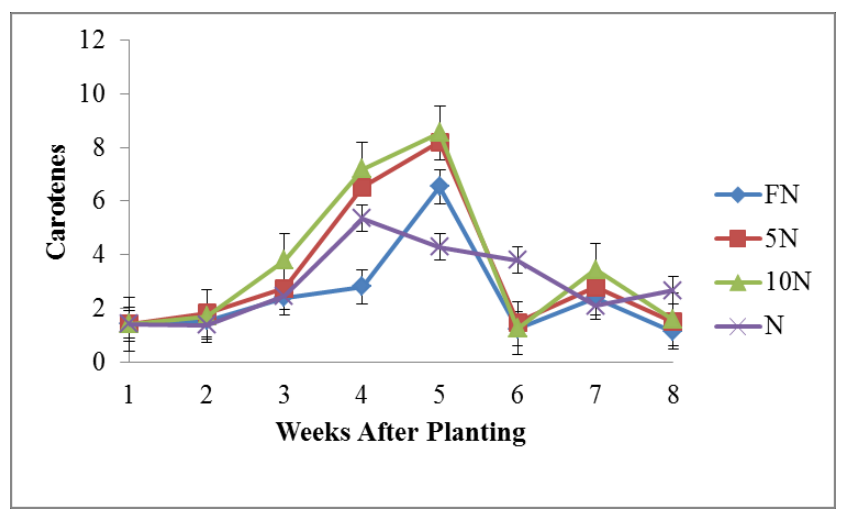

Fig. $4 \mathrm{~b}$. The effect of nitrogen nutritional stress on the carotene content of Zea mays measured at different periods

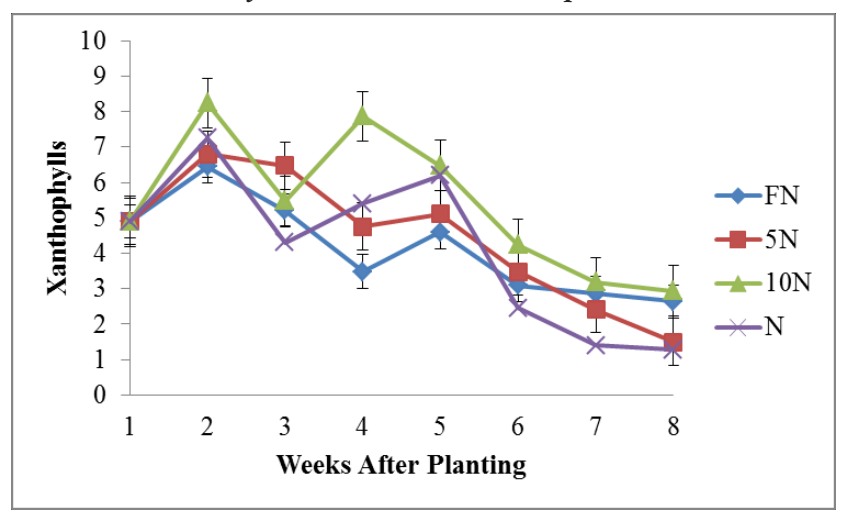

Fig. 5b. The effect of nitrogen nutritional stress on the xanthophyll contents of Zea mays measured at different periods 


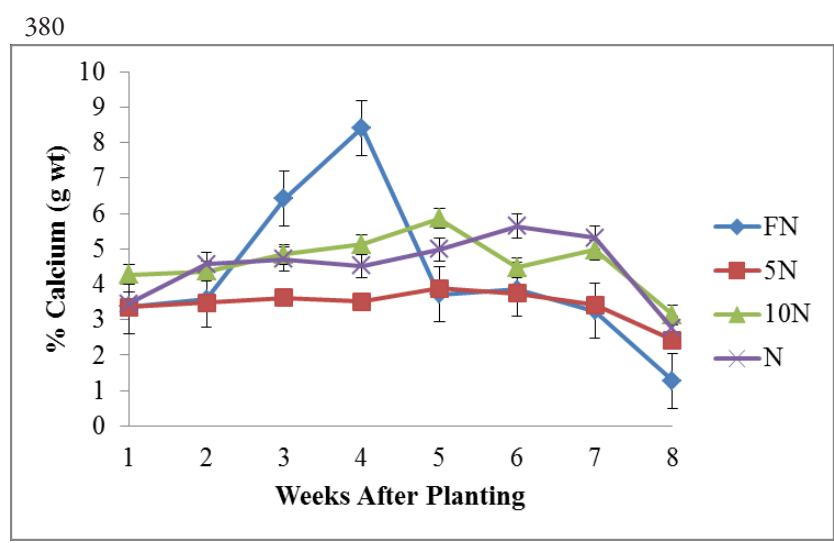

Fig. 6a. The effect of nitrogen nutritional stress on the percentage calcium content of Vigna unguiculata measured at different periods

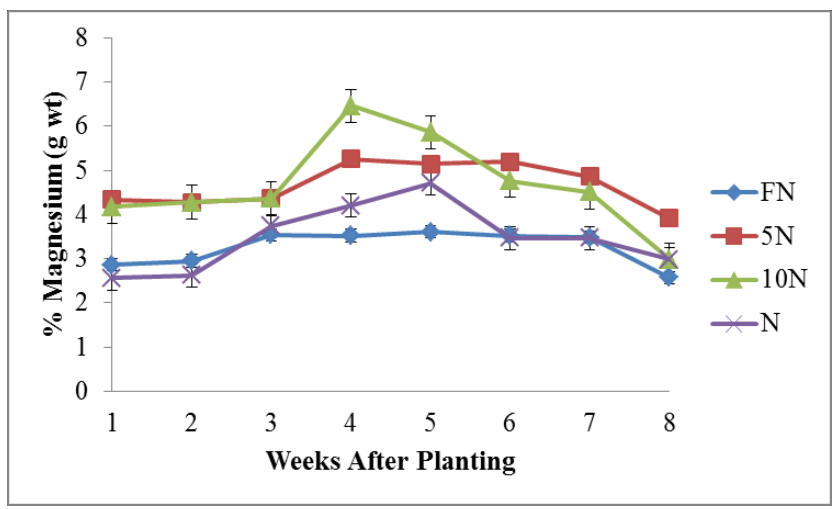

Fig. 7a. The effect of nitrogen nutritional stress on the percentage magnesium content of Vigna unguiculata measured at different periods

sults of the ANOVA showed that there was no significant difference $(p>0.05)$ in FN, X10N and $-\mathrm{N}$ treatments while $\mathrm{X} 5 \mathrm{~N}$ was significantly different. Meanwhile, the calcium and magnesium contents of maize followed similar inconsistent patterns as shown in Fig. $6 \mathrm{~b}$ and $7 \mathrm{~b}$ respectively. At the end of the experiment, $\mathrm{X} 10 \mathrm{~N}$ was observed to have the highest calcium content, followed by X5N while FN recorded the lowest. Results of the ANOVA showed that there was no significant difference $(p>0.05)$ in all the treatments. However, X10N was observed to have the highest magnesium content, followed by $\mathrm{X} 5 \mathrm{~N}$ while $-\mathrm{N}$ recorded the lowest. Results of the ANOVA showed that there was no significant difference $(p>0.05)$ in FN, X10N and X5N treatments. However, $-\mathrm{N}$ was significantly different.

\section{Discussion}

The relationship between photosynthetic capacity and leaf nitrogen concentration had been documented by $\mathrm{Ev}$ ans and Seemann (1989) Also, Alt et al. (2000) reported a correlation between photosynthetic capacity and leaf nitrogen content in Vernonia herbacea. Nitrogen deficiency leads to disruption of the fine structure of chlorophyll and instability of the pigment protein complex (Reddy et al., 2007). The above accounted for the chlorosis, necrosis, ab-

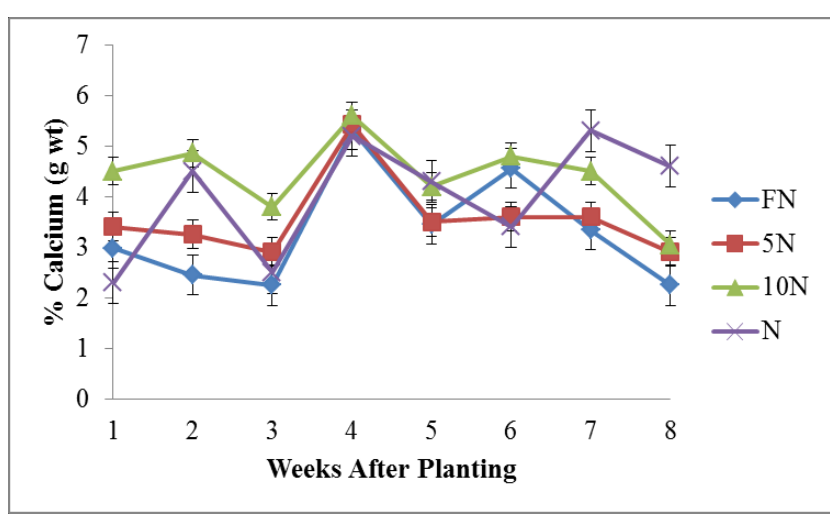

Fig. 6b. The effect of nitrogen nutritional stress on the percentage calcium content of Zea mays measured at different periods

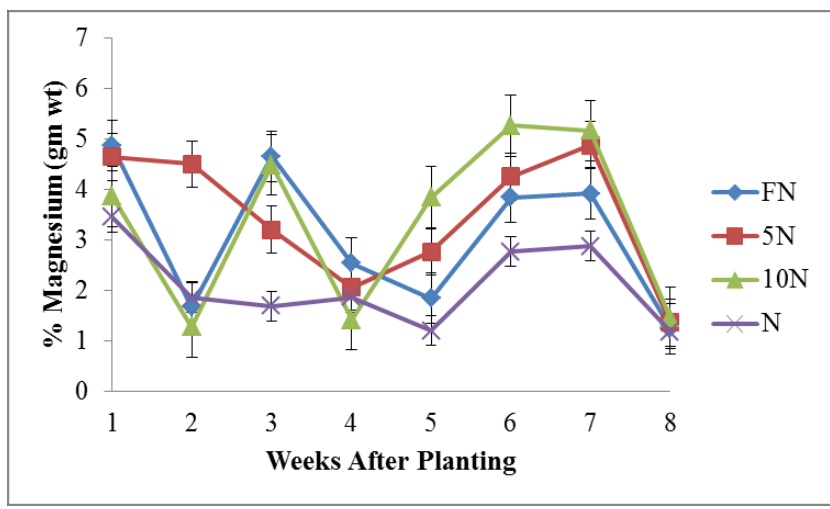

Fig. 7b. The effect of nitrogen nutritional stress on the percentage magnesium content of Zea mays measured at different periods

scission and senescence of older leaves noticed in the latter part of the experiment in -N plants in Vigna unguiculata. The chlorosis spreads from older to younger leaves because of the mobility of nitrogen from older to younger leaves (Mengel et al., 1987). According to Gumbach (1982), chlorophyll is a precursor for carotenoid formation, the higher the chlorophyll, the higher the carotenoid content. The total chlorophyll contents, carotenes and xanthophylls were determined by chlorophyll 'a' contents as the patterns of accumulations were similar. This substantiates the observation made in the total chlorophyll accumulation noticeable in X5N plants compared to the FN plants. Unlike in the carotene accumulation, FN plants had the highest accumulation of xanthophylls because the former is easily oxidized in light (Adelusi, 1978) while the lowest was observed in X10N plants. This results in the acceleration in the rate of purple pigment anthocyanin in the leaves of FN plants with early defoliation and suppressed shoot growth. The carotenoids which include orange carotenes and yellow xanthophylls act in protecting the chlorophyll from photo-destruction and photo -oxidation.

The higher accumulation of calcium in FN plants substantiates the earlier findings of Ashraf et al. (1999) while working on sorghum; they reported that calcium had a strong association with nitrogen stressed plants. A com- 
parison of calcium ion and magnesium ion concentrations in both optimal and stressed conditions reveals that the two ions show antagonism in uptake (Ashraf et al., 2000). The calcium and magnesium contents in cowpea followed inconsistency patterns. This confirms the result of the experiment indicating the highest magnesium accumulation in X10N plants while calcium accumulation was observed to be the relatively low. There is a correlation between nitrogen and magnesium accumulation as magnesium ion plays a vital role in chlorophyll biosynthesis (Walker et al., 1991), protein synthesis and photosynthesis (Marschner et al., 1997). This accounted for the high accumulation of chlorophyll in the X10N plants.

Nitrogen nutrition influences photosynthesis in three main ways: Nitrogen deficiency may affect the quantity, structure and composition of the photosynthetic apparatus since this account for most of the nitrogen in the leaves (Adjei et al., 2008). Nitrogen nutrition affected the functional organization of chlorophylls in the leaves, large increase in the number of cyclic photophosphorylation (PS1) reactions centers were observed which fully accounted for the increase in leaf chlorophyll content noticeable in the X10N plants. However, Cartel (2000) postulated that increased growth of maize plants at optimal nitrogen nutrition is related to greater capacity for photosynthesis and translocation in mature leaves and possibly increased capacity for sucrose metabolism in expanding leaves. This supported the observations recorded in the FN plants. Efficient translocation of photosynthate from source to sink organs is the key factor driving plant growth and increased crop yield (Dakora, 2003; Cornu, 2007). Photosynthesis was reported to be affected by sink strength as increased photosynthate supply is required to meet increasing demand for photo-assimilates during early vegetative growth and seed development in Zea mays (Richards, 2000). Strong positive correlations have been found between the photosynthetic capacity of leaves and their nitrogen content, most of which is used for synthesis of components of the photosynthetic apparatus (Gastal et al., 2002). This substantiated the result of the total chlorophylls accumulation in the X10N plants.

In contrast to the regimes of cowpea, the total chlorophyll contents in maize were determined by the patterns of chlorophyll ' $b$ ' accumulations. The strength of chlorophyll 'a' was established as it appeared dictating the growth patterns of other photosynthetic apparatus. The range of concentration of a particular element varies widely between different plants and is also affected by the conditions under which the plants are grown (Adeyeye, 2002). Unlike in the regimes of cowpea, the magnesium and calcium contents in maize followed similar patterns.

The calcium content in the leaves of X10N plants was the highest throughout the course of the experiment. However, it has been observed that high concentration of calcium ions increase the complex carbohydrates contents of the tissues (Beckenbach et al., 1996). Also, calcium in form of calcium pectate is a constituent of the middle lamellae of cell wall, vacuole and endoplasmic reticulum (Evans et al., 1991). Calcium concentration is usually significantly lower in monocotyledonous plants compared to the dicotyledonous plants both in the field and when grown in solution culture (Marshner, 1997). The highest calcium content in the photosynthetically active leaves of the $\mathrm{X} 10 \mathrm{~N}$ probably bears upon its physiological function in the plant, hence, stabilizing the functions of the membranes of mitochondria and chloroplast where electrons are transported (Roberts et al., 1992). This confers greater advantage on the accumulation of photosynthetic apparatus noticeable in the $\mathrm{X} 10 \mathrm{~N}$ compared to the other plants. Again, this process influences the uptake, transport and the redistribution of calcium ions which is partially mobile through the xylem and phloem (Taiz et al., 1998). The highest magnesium content in the $\mathrm{X} 10 \mathrm{~N}$ confers a physiological advantage on $\mathrm{X} 10 \mathrm{~N}$ as magnesium ion plays a prominent role in chlorophyll biosynthesis and as activator of enzymes affecting carbohydrate metabolism (Adeyeye, 2002). These results were in agreement with the chlorophyll accumulation in the X10N plants. The positive correlation between nitrogen and magnesium was however established in the $-\mathrm{N}$ plants which show a distinct lower accumulation of chlorophyll, hence the leaves showed interveinal chlorosis orchestrated by accumulation of anthocyanin pigment, necrosis and reduction of growth.

\section{Conclusions}

The pattern of accumulation of photosynthetic apparatus in both maize and cowpea follow a similar fashion. Chlorophyll a dictated the growth pattern of chlorophyll b, total chlorophyll, carotene and xanthophylls in both maize and cowpea. This led to increase in photosyhnthates and by implication contributed immensely to the growth and development of plants. The strength of chlorophyll 'a' had been established as it appeared dictating the growth patterns of other photosynthetic apparatus. Calcium concentration had been proven to be significantly lower in monocotyledonous plants compared to the dicotyledonous plants both in the field and when grown in solution culture. Hence, calcium concentration was significantly lower in Zea mays plants compared to the regimes of $V i$ gna unguiculata. The higher potassium accumulation in the maize seedlings could be attributed to its physiological role in the development of seed and husk in cereals. This study has to a larger extent contributed to the relationship between nitrogen nutritional stress, metabolic activities and photosynthetic apparatus in the species under study.

\section{References}

Adelusi AA (1978). Heat-induced quantitative changes in the growth, photosynthetic apparatus, plastid pigments and flavonoids of Zea mays Linn.variety N.S.I. and Vigna unguicu- 
382

lata (Linn) Walp, Obafemi Awolowo University, Ile-Ife, M. Sc. Thesis.

Adeyeye EI, Adejuyo OO, Pak AA (2002). Journal of Science Research 45:10-11.

Alt AP, Makini F, Kidula N (2000). Effect of intercropping legume with maize on soil fertility and maize yield. Plant and Soil 54:109-115.

Ashraf SD, MC Nelly (1999). The effects of growing beans together with maize on incidence of bean diseases and pests. Neth J Plant Pathol 78:12-18.

Ashraf, SD, Liebman M, Davis AS (2000). Intergration of soil, crop and weed management in low external input farming systems. Weed Res 40:27-47.

Bray EA, Bailey-Serres (2000). Responses to abiotic stress, 1158-1203 p. In: Rockville MD (Ed.). Biochemistry and Molecular Biology of Plant, American Society of Plant Physiologists.

Carterl GA (2000). Leaf optical properties in higher plants: Linking spectral characteristics to stress and chlorophyll concentration. American Journal of Botany 88:677-684.

Cornu JY (2007). Copper concentration in plants and in the rhizosphere as influenced by the iron contents of tomato (Lycopersicum esculentum L.). Plant and Soil 292:63-77.

Dakora FD (2003). Defining new roles for plants and rhizobial molecules in sole and mixed plant cultures involving symbiotic legumes. New Phytology 158:39-49.

Evans DE, Briars SA, Williams LE (1991). Active calcium transport by plant cell membranes. J Exp Bot 42:285-305.

Evans JR (1989). Photosynthesis and nitrogen relationship in leaves of $\mathrm{C}_{3}$ plants.

Evans JR, Seeman JR (1989). Environmental effects on photosynthesis, nitrogen-use efficiency, and metabolic pools in leaves of sun and shade plants. Plant Physiol 84:796-802.

Gastal KL, Bemaire GC (2002). Row spacing effect of nitrogen fixation, nitrogen yield and soil nitrogen uptake of intercropped cowpea and maize. J Plant and Soil 11:17-23.

Gastal TR (2002). Effect of alfalfa leaf extracts and phenolic allelochemicals on early seedling growth and root morphology of alfalfa and barynarg grass. Crop Prot 5:1077-1082.

Gumbach LM (1982). Performance of maize-soybean intercrops combinations in the tropics: Results of a multi-location study. Field Crop Res 5:147-161.

Hartung WS, Wilkinson, Davies WJ (1998). Factors that regulate absiscic acid concentrations at the primary site of action at the guard cell. J Mol Microbiol Biotechnol 1:231-242.

Hasegawa PM, Bressan RA, Zhu JK, Bohnert HJ (2000). Plant cellular and molecular responses to high salinity. Annu Rev Plant Physiol Plant Mol Biol 51:463-499.
Hewitt EJ(1952). Sand and water culture methods used in the study of plant nutrition. Commonw Bur Horts Plantatio Crops Grt Brt Tech Comm No.22.

Hong SW, Vierling E (2000). Mutants of Arabidopsis thaliana defective in the acquisition of tolerance to high temperature stress. Proc Natl Acad Sci USA 97:4392-4397.

Lambers J, Jones TL (1998). Plant physiological ecology. Springer-Verlag, New York.

Levitt J (1980). Responses of plants to environmental stresses. Academic Press, New York

Machlis and Torrey (1956). Primary nutrients and plant growth. In: Essential Plant Nutrients, North Carolina Department of Agriculture.

Marschner H (1995). Mineral nutrition of higher plants. Academic Press, London, $889 \mathrm{p}$.

Marschner H (1997). Mineral nutrition of higher plants, $2^{\text {nd }}$ ed. Acad. Press Inc., London.

Mengel RS, Kirky AA (1987). Effect of planting density and plant arrangement pattern on growth and yields of maize $($ Zea mays L) and Soybean (Glycine max L. Merr) grown in mixtures. J Agric Sci (Camb) 112:1-8.

Pollock FT, Cairns MD (1991). Nitrogen transfer and dry matter production in soybean and sorghum mixed cropping systems at different population densities. Soil Sci Plant Nutri 36:233-241.

Reddy MA, Dakora FD(2007). Yield components of nodulated cowpea (Vigna unguiculata) and maize (Zea mays) plants grown with exogenous phosphorus in different cropping systems. Australian J Exp Agric 47:583-589.

Richards RA (2000). Influence of mutation induction on chemical composition of cowpea African J of Biotec 6(18).

Roberts LA, Hooks JD, Edwards SM (1992). Intercrop performance of Pearl millet, Amaranthus, Cowpea, Soybean and Guar in Response to Planting Pattern and Nitrogen Fertilization. Agronomy Journal 86:1097-1102.

Salisbury FB, Ross CW (1991). Plant Pyhsiology. Wadsworth Inc., Belmont.

Schinozaki K (2000). Molecular responses to dehydration and low temperature: Curr Opinion in Plant Biol 217-223 p.

Statistical Analysis System (2003). SAS, 2003, US Incorp.

Taiz L, Zeiger E (1998). Plant Physiology. $2^{\text {nd }}$ ed. Sinaeur Assoc. Inc. Publ, Sunderland.

Walker TW, Buresh RJ, De Datta SK (1991). Nitrogen dynamics and management in rice legume cropping systems. Adv Agronom 45:1-49. 